\title{
Basal cortisol in asthmatics on two different doses of fluticasone propionate
}

\author{
Cláudia R. de Andrade, ${ }^{1}$ Paulo Augusto M. Camargos, ${ }^{2}$ Cássio da C. Ibiapina, ${ }^{3}$ \\ Laura Maria de L. B. F. Lasmar4
}

\begin{abstract}
Objectives: To evaluate basal plasma cortisol in persistent asthmatics on inhaled fluticasone propionate $200 \mathrm{mcg} /$ day and $300 \mathrm{mcg} /$ day.

Methods: Asthma diagnosis and classification was based on Global Initiative for Asthma recommendations. Patients aged 11 years old or less received fluticasone propionate $200 \mathrm{mcg} /$ day and those older than 11 years received 300 $\mathrm{mcg} /$ day. After 10 weeks of treatment, plasma cortisol levels were monitored to evaluate the hypothalamic-pituitary-adrenal axis.
\end{abstract}

Results: Forty-one patients ( $65.9 \%$ males) aged 6 to 18 years old were evaluated. No statistical differences were found between plasma cortisol levels in patients who received $200 \mathrm{mcg} /$ day $(n=13)$ and those who received 300 $\mathrm{mcg} /$ day $(\mathrm{n}=28)$.

Conclusions: Our results show that low and moderate doses of fluticasone propionate do not cause adrenal suppression.

J Pediatr (Rio J). 2008;84(4):373-376: Asthma, cortisol, corticosteroids.

\section{Introduction}

The literature reports that inhaled corticosteroids rarely cause hypothalamic-pituitary-adrenal axis (HPA) suppression in patients with asthma when they are using at the dosages habitually recommended. With relation to fluticasone propionate (FP), doses of up to $400 \mathrm{mcg} /$ day are considered safe for the pediatric population. ${ }^{1-4}$ However, the possibility of adrenal suppression, even at lower doses of corticosteroids, has been described. ${ }^{5}$

One method used to evaluate the condition of the HPA is to measure basal cortisol. The highest levels of cortisol are observed at 8:00 hours, due to its circadian variation. Testing basal cortisol at this time of day can be useful for an initial assessment of adrenal function and, if abnormal, further tests can be run.

To date, there are few studies in the literature that have compared the basal cortisol levels of children and adolescents with persistent asthma who are on low to moderate doses of FP.

The objective of this study was to evaluate basal cortisol levels in asthmatic children and adolescents on two different dosages of FP.

\section{Methods}

\section{Study location and population}

The study was carried out between January and March of 2006 at the Pediatric Pulmonology Outpatient Clinic of the

1. Doutoranda. Programa de Pós-Graduação em Ciências da Saúde da Criança e Adolescente, Faculdade de Medicina, Universidade Federal de Minas Gerais (UFMG), Belo Horizonte, MG, Brazil.

2. Professor titular, Departamento de Pediatria, Faculdade de Medicina. Chefe, Unidade de Pneumologia Pediátrica, Hospital das Clínicas, UFMG, Belo Horizonte, MG, Brazil.

3. Professor adjunto, Departamento de Pediatria, Faculdade de Medicina, UFMG, Belo Horizonte, MG, Brazil.

4. Professora adjunta, Departamento de Pediatria, Faculdade de Medicina, UFMG, Belo Horizonte, MG, Brazil.

No conflicts of interest declared concerning the publication of this article.

Suggested citation: de Andrade CR, Camargos PA, Ibiapina CC, Lasmar LM. Basal cortisol in asthmatics on two different doses of fluticasone propionate. J Pediatr (Rio J). 2008;84(4):373-376.

Manuscript received Jan 30 2007, accepted for publication Apr 092008.

doi:10.2223/JPED.1798 
Table 1 - Descriptive characteristics of the patients and mean basal cortisol for a group on $200 \mathrm{mcg} /$ day of fluticasone propionate (age $\leq 11$ years) and a group on $300 \mathrm{mcg} /$ day

\begin{tabular}{|c|c|c|c|}
\hline \multirow[b]{2}{*}{ Variables } & \multicolumn{2}{|c|}{ Dosage } & \multirow[b]{2}{*}{$\mathbf{p}$} \\
\hline & $200 \mathrm{mcg} / \mathrm{day}$ & $300 \mathrm{mcg} / \mathrm{day}$ & \\
\hline \multicolumn{4}{|l|}{ Sex } \\
\hline Male & 10 & 17 & 0.32 \\
\hline Female & 3 & 11 & \\
\hline \multicolumn{4}{|l|}{$\mathrm{FEV}_{1}(\%)$} \\
\hline Mean (SD) & $83.09(2.36)$ & $79.83(7.64)$ & 0.32 \\
\hline \multicolumn{4}{|c|}{ Basal cortisol (mcg/dL) } \\
\hline Mean (SD) & $11.08(4.04)$ & $11.09(4.06)$ & 0.99 \\
\hline Variation & $5.31(19.55)$ & $6.02(21.57)$ & \\
\hline
\end{tabular}

$\mathrm{FEV}_{1}=$ forced expiratory volume in 1 second; SD = standard deviation.

Campos Sales Health Center, belonging to the Municipal Health Department (Secretaria Municipal de Saúde) of Belo Horizonte, MG, Brazil. A total of 41 children and adolescents with persistent asthma were enrolled consecutively.

\section{Inclusion and exclusion criteria}

The sample included patients aged from 6 to 18 years and 11 months with a diagnosis of moderate persistent asthma according to the criteria defined by the Global Initiative for Asthma (GINA). ${ }^{6}$ Patients were excluded if they reported that during the 4 weeks preceding the study they had had systemic corticosteroids, inhaled corticosteroids therapy, nasal topical, dermatological and ophthalmological corticosteroids, and if they used systemic or topical corticosteroids during the study period and those with coexisting diseases.

\section{Monitoring and treatment}

The patients received FP sprays for oral inhalation (Flixotide ${ }^{\circledR}$, GlaxoSmithKline, Brazil, $50 \mathrm{mcg} /$ puff), at a dosage of $200 \mathrm{mcg} /$ day for those aged $\leq 11$ years and at a dosage of $300 \mathrm{mcg} /$ day for those over 11, using a pear-shaped valved spacer with a volume of $650 \mathrm{~mL}$ (Flumax $\left.{ }^{\circledR}\right){ }^{2,6}$ Patients underwent clinical evaluation every 2 weeks for 10 weeks in order to detect any clinical abnormalities that might be associated with taking the medication. Additionally, adherence to treatment was monitored by systematically weighing the metered-dose inhalers on an analytic balance (Mast, Brazil) with a precision of 0.23 to $1 \mathrm{~g}$ at every consultation.

\section{Determination of basal cortisol}

Cortisol was measured after 10 weeks' treatment. Patients were instructed to take their inhaled corticoid up to around 12 hours before the blood sample would be taken, at 8:00 hours sharp the next day, in the same laboratory and using direct chemiluminescence (ADVIA Centaur System, Bayer
Healthcare LLC; Tarrytown, NY, United States) to assay cortisol, with normal reference values of 5.0 to $25.0 \mathrm{mcg} / \mathrm{dL}$. On the day before the cortisol assay, patients underwent spirometry to measure forced expiratory volume in one second $\left(\mathrm{FEV}_{1}\right)$. Measurements were taken using an SBG-SDI Diagnostics spirometer (Easton, United States) and equations published by Polgar and Knudson were taken as reference values.

\section{Statistical analysis}

Frequency distributions were analyzed using the chi-square test, Student's $t$ test, Fisher's exact test and their respective $95 \%$ confidence intervals. The software used was Epi-Info 6.04 and the significance level was $p<0.05$.

\section{Ethical considerations}

The study protocol and the informed consent were approved by the Ethical Research Committee of the Universidade Federal de Minas Gerais.

\section{Results}

A total of 41 patients ( $65.9 \%$ male) were evaluated, 13 $(31.7 \%)$ were aged $\leq 11$ years. Mean $\mathrm{FEV}_{1}$, measured on the day prior to the cortisol assay, was similar for both groups, 83.09 and $79.83 \%$ respectively $(p=0.32)$. The clinical assessments carried out over the 10 weeks' treatment did not detect any signs or symptoms compatible with adverse effects from inhaled corticosteroids, such as hoarseness or oropharyngeal candidiasis.

All of the patients assessed gave a blood sample for basal cortisol assay. No statistically significant difference was observed between mean basal cortisol levels of patients given 300 and $200 \mathrm{mcg} /$ day, as presented in Table 1.

With relation to the weights of the metered-dose inhalers at study outset, during follow-up and at the end of treatment, 
no statistically significant difference was detected between the two groups ( $p \geq 0.15$ ).

\section{Discussion}

The risk of adverse effects from inhaled corticoids depend on the route of administration, dose, potency, bioavailability, first-pass hepatic metabolism and half-life. ${ }^{1}$

The adverse effects of these medications can be identified by the presence of hoarseness, oropharyngeal candidiasis, delayed growth velocity ${ }^{7}$ and biochemical findings of adrenal suppression. ${ }^{1}$ These are recognizedly more sensitive than clinical assessment. ${ }^{5,8-12}$

Eid et al., ${ }^{5}$ assessed 62 asthmatic children with no symptoms suggestive of adrenal dysfunction who were taking FP at doses from 176 to $1,320 \mathrm{mcg} /$ day, finding that basal cortisol was abnormal in $36 \%$ of them. Noteworthy in that study was the fact that $17 \%$ of those on low doses of FP had low basal cortisol values, in contrast with this study. It should be taken into consideration that there is not yet a consensus in the literature on pediatric reference values for basal cortisol, which makes comparison between studies more difficult. Sim et al. ${ }^{11}$ assessed 50 asthmatic children and adolescents on elevated doses of FP ( $\geq 1,000 \mathrm{mcg} /$ day). These authors found that basal cortisol was abnormal in $72 \%$ of the patients even though they were asymptomatic. Nevertheless, the clinical relevance of these findings has not been established since there have been no reports of severe events due to adrenal insufficiency in children using inhaled corticoids at the dosages habitually recommended. ${ }^{1}$

The measures most often used to assess adrenal function are basal cortisol, urinary and stimulus tests, as the metapyrone test, the standard stimulation with corticotropin test and the insulin tolerance test (ITT). Of these, the ITT is considered the gold standard since it allows dynamic assessment of the HPA axis. ${ }^{9}$ However, the measurements involved are more complex, it involves increased risk of complications, demands monitoring and is contraindicated for patients with heart diseases and the elderly. Furthermore, studies with children are rarer than those involving adult population.

The advantages of basal cortisol over other tests for assessing adrenal function are accessible cost, its increased practicality and safety and, because of these reasons, it has been adopted in several studies. ${ }^{5,11,13,14}$ Nevertheless, it offers reduced sensitivity for detecting HPA axis abnormalities.

In this study, basal cortisol levels were normal in all of the patients assessed, irrespective of the dose employed. It should be remembered that the absence of a difference between the weights of the medication inhalers indicated that compliance was similar between the two groups. Furthermore, the $\mathrm{FEV}_{1}$ values were also similar for both groups, indicating that the degree of functional control was also similar.
This finding is interesting, since patients with accentuated airway obstruction absorb less inhaled corticosteroids and, consequently, there is a reduced possibility of adrenal suppression.

We did not measure basal cortisol before starting inhaled corticosteroids therapy, since in clinical practice there is no need to do so routinely. Our study is more an expression of the clinical context, which is also the reason for not including a control group. It should be pointed out that, in work published by Eid et al. ${ }^{5}$ and Sim et al., ${ }^{11}$ there were also no control groups, and neither was cortisol measured prior to treatment.

With relation to the study period, the patients' basal cortisol after 10 weeks' FP reflects the HPA axis under the influence of medication and, therefore, probably does not have any relationship with cortisol levels prior to treatment. It has been reported that levels of adrenocorticotrophic hormone (ACTH) rapidly (2-3 minutes) increase synthesis and secretion of basal cortisol. Furthermore, when ACTH drops, cortisol also decreases rapidly. ${ }^{12}$ There is a report of adrenal suppression after 5 weeks' fluticasone use. ${ }^{15}$

With relation to selection and sampling, the study consecutively enrolled 41 patients referred to a pediatric pulmonology outpatient clinic with a diagnosis of persistent moderate asthma. There is a possibility that the absence of any difference between the mean basal cortisol levels of patients on 200 and $300 \mathrm{mcg} /$ day is a result of the limited sample. However, if the difference between the means was indeed exactly what we found, i.e., 0.01, we would have needed 350 thousand patients in each group. If it was 1.0 , it would have been 355 in each group, which would have meant that it would not have been viable to carry out the study.

The finding of cortisol concentrations within normal reference limits is probably associated with the doses used, which were those habitually recommended for the treatment of mild/ moderate persistent asthma. Studies to assess the HPA axis after greater duration of FP use at low and moderate doses should be stimulated in order to improve knowledge about the effects on the HPA axis.

\section{References}

1. Lipworth BJ. Systemic adverse effects of inhaled corticosteroid therapy: a systematic review and meta-analysis. Arch Intern Med. 1999;159:941-55.

2. Masoli M, Weatherall M, Holt S, Beasley R. Systematic review of the dose-response relation of inhaled fluticasone propionate. Arch Dis Child. 2004;89:902-7.

3. Ferguson AC, Spier S, Manjra A, Versteegh F, Mark S, Zhang P. Efficacy and safety of high-dose inhaled steroids in children with asthma: a comparison of fluticasone propionate and budesonide. J Pediatr. 1999;134:422-7. 
4. Lipworth BJ, Clark DJ, MacFarlane LC. Adrenocortical activity with repeated twice daily dosing of fluticasone propionate and budesonide given via a large volume spacer to asthmatic school children. Thorax. 1997;52:686-9.

5. Eid N, Morton R, Olds B, Clark P, Sheikh S, Looney S. Decreased morning serum cortisol levels in children with asthma treated with inhaled fluticasone propionate. Pediatrics. 2002;109: 217-21.

6. National Institutes of Health and National Heart, Lung, and Blood Institute. Global Initiative for Asthma. Global Strategy for Asthma Management and Prevention. Bethesda, Md: National Institutes of Health; 2002. NIH Publication 02-3659.

7. Arend EE, Fischer GB, Debiasi M, Schmid H. Inhaled corticosteroid treatment and growth of asmathic children seen at out patient clinic. J Pediatr (Rio J). 2006;82:197-203.

8. O'Byrne PM, Pedersen S. Measuring efficacy and safety of different inhaled corticosteroid preparations. J Allergy Clin Immunol. 1998;102:879-86.

9. Dickstein G. The assessment of the hypothalamo-pituitary-adrenal axis in pituitary disease: are there short cuts? J Endocrinol Invest. 2003;26:25-30.

10. Dunlop KA, Carson DJ, Steen HJ, McGovern V, McNaboe J, Shields MD. Monitoring growth in asthmatic children treated with high dose inhaled glucocorticoids does not predict adrenal suppression. Arch Dis Child. 2004;89:713-6.

11. Sim D, Griffiths A, Armstrong D, Clarke C, Rodda C, Freezer N. Adrenal suppression from high-dose inhaled fluticasone propionate in children with asthma. Eur Respir J. 2003;21: 633-6.
12. Zöllner E. Hypotalamic-pituitary-adrenal axis suppression in asthmatic children on inhaled corticosteroids: part 1. Which test should be used? Pediatr Allergy Immunol. 2007;18:401-9.

13. Lipworth BJ, Jackson CM. Safety of inhaled and intranasal corticosteroids: lessons for the new millennium. Drug Saf. 2000; 23:11-33.

14. De Benedictis FM, Del Giudice MM, Vetrella M, Tressanti F, Tronci A, Testi R, et al. Nebulized fluticasone propionate vs. budesonide as adjunctive treatment in children with asthma exacerbation. J Asthma. 2005;42:331-6.

15. Mahachoklertwattana P, Sudkronrayudh K, Direkwattanachai C, Choubtum L, Okascharoen C. Decreased cortisol response to insulin induced hypoglycaemia in asthmatics treated with inhaled fluticasone propionate. Arch Dis Child. 2004;89:1055-8.

Correspondence:

Paulo Augusto Moreira Camargos

Departamento de Pediatria - Faculdade de Medicina

Universidade Federal de Minas Gerais

Avenida Professor Alfredo Balena, 190/4061

CEP 30130-100 - Belo Horizonte, MG - Brazi

Tel. : +55 (31) 3409.9772

Fax: +55 (31) 3409.9664

E-mail: pauloamcamargos@gmail.com, pcamargs@medicina.ufmg.br 